Анна Владимировна Гик

Россия, Институт русского языка им. В.В. Виноградова РАН

\title{
Система пунктуации в драме Ильи Зданевича «Янко крУль албАнскай»
}

Ключевые слова: Илья Зданевич, русский футуризм, заумь, поэтическая грамматика. Key words: Ilia Zdanevich, Russian futurism, zaum, poetic grammar.

\begin{abstract}
The text of the drama "Janko krUl' albAnskaj" by Ilia Zdanevich is the embodiment of the ideas of Russian futurism on the creation of a new poetic language, and reflects discussions on spelling reform relevant to the beginning of the $20^{\text {th }}$ century. Punctuation in the text of avant-garde works plays a special role. By minimal means, using small number of punctuation marks in principle, the author achieves structural division of the text, which contributes to the understanding of its basic constructions - in particular, residual emotions.
\end{abstract}

Драму Зданевича «Янко крУль албАнскай» (1918 г.) [Zdanevič 2008: 479-500] необходимо рассматривать в целом как языковой эксперимент. Первое, на что обращает внимание читатель и исследователь - это особое использование в художественном произведении классической системы знаков препинания. «Память» драматического жанра позволяет выделить в произведении, состоящем из 20 страниц, три чередующихся типа текста. Они соответствуют структуре драмы: 1) речь «хазяина» (распорядителя театральной постановки); 2) речь героев драмы; 3) ремарки, уточняющие или дополняющие детали действия и характеристики героев. Речь распорядителя и ремарки написаны фонетической транскрипцией русского языка: «граждани» - граждане, «изык» - язык и т.п. Речь героев, за исключением отдельных фраз, написана на зауми. Заумные слова не имеют определенной семантики, их значение контекстно и ситуативно обусловлено.

Однако отсутствие словарных лексических единиц русского языка не означает полного отсутствия смысла произведения. Текст драмы «Янко крУль албАнскай» оформлен как драматическое произведение среднего объема. Средствами выражения смысла становятся визуальное оформление 
текста, особенности его построения (оформление абзаца, предложения), в том числе использование пунктуационных знаков. Заумный текст передает эмоциональное состояние героев, а факты и события приходится читателю додумывать. Зданевич использует ядерные конструкции языка, например, алфавит. Совокупность знаков для письма, расположенных в определённом порядке, имеет одновременно магическую и прагматическую функцию представления текста. Некоторые строки драмы представляют собой перечисление букв русского алфавита. Мы находим небольшое количество примеров, когда за набором букв вычитываются слова - за образованием «дупурапак» [Zdanevič 2008: 487], как кажется читателю, стоит лексема «дурак». Зданевич использует максимально разнообразное сочетание букв в заумных словах, которое выбивается из типовых словообразовательных моделей русского языка: «хювот», «утуфпатам», «викшытабли». Особую роль в выстраивании текста автор придает пунктуации, используемой по экспериментальным законам зауми, а не по правилам русского языка.

Во всех типах текста автор использует упрощенный синтаксис. Предложения начинаются с маленькой буквы. Концом предложения является конец строки. Благодаря такой форме драма выглядит как поэтическое произведение. В тексте применяются разнообразные способы организации строки: использование алфавита (аб бевегбевиг ге де е), рифменные сочетания заумных слов (козот зывот хювот // вовот жавот фавот). Некоторые слова соотносятся с детским лепетом (папася мамася), встречаются футуристические слова из одних согласных (сглв сгтп цгтв мнбл бн) и др. Обилие приемов создает дополнительные трудности для понимания произведения, и в этом отношении автор соблюдает футуристические заповеди, которые и оформлены экспериментальным образом - без знаков препинания, без заглавных букв: «чтоб писалось туго и читалось туго неудобнее смазных сапог или грузовика в гостиной» [Kručenyh, Hlebnikov 2000].

Переход от одного типа текста к другому (например, от ремарок к речи героев) осуществляется обычно с помощью пробельной строки. В ремарках не используются выделения букв полужирным шрифтом, что является их отличительным признаком. В речи «хазяина» и других персонажей обильно используется это выделение - как для удобства декламации, так и для создания визуальной формы [Gik 2019]. Помимо выделения полужирным шрифтом в тексте используется увеличение шрифта как для слов, так и для отдельных букв внутри слова (рис. 1), что служит задачам прежде всего хоровой декламации - часть произведения исполняется хором («аркестрам»).

Ильязд (псевдоним Ильи Зданевича) использует в тексте следующие знаки препинания: скобки, вопросительный знак, тире, а также вертикальную черту. Полностью отсутствуют другие знаки: точка, запятая, восклицательный знак, многоточие, кавычки, точка с запятой. Интересно отсутствие 
восклицательных знаков, с помощью которых проще было бы передавать эмоциональное содержание высказывания. Очевидно, автор поставил задачу обойтись минимальными пунктуационными средствами. Этот же способ использования знаков препинания сохраняется и в последующих драмах цикла «Аслаабличье» - за исключением последнего произведения «Лидантю фарам», где автор обогатил применяемый им заумный язык и придумал новые функции и для неиспользуемых ранее знаков препинания - например, точек. Напомним, что именно с этого нестандартного использования точек в «Лидантю» начался знаменитый спор Ильязда с летристами и современными визуальными поэтами в 1946 г.

\section{бМиМАс бмиМАс чшіх Ђъьы июя $\odot$ ижыцаа бвгд вап лыс Гун лидигуивирол самбо - Iอ Hars ча виона}

Рисунок 1. Применение увеличенного шрифта и таблиц [Zdanevič 2008: 493]

Скобки в тексте (как открывающие, так и закрывающие) применены тринадцать раз. Скобки в речи «хазяина» используются обычным способом, для конкретизации: «(па нужэ смысла ни приважу)» (как нам кажется, эту строчку можно понять так: по необходимости смысла не привожу) [Zdanevič 2008: 481]. В заумной речи персонажей открывающая скобка вместе с тире «(-» составляют специфический символ, который может быть выделен шрифтом, т.е. быть ударным, и, возможно, служит неким аналогом неиспользуемого в драме восклицательного знака или современного «смайлика». Этот знак обычно употребляется в конце строки. Заумное слово с этим знаком может состоять из нескольких букв: (-кикики, (-епити; или из одной: (-т. Вероятно, что автор призывает интонировать предложение с помощью такого приема - не с помощью отдельного знака (например, восклицательного), а с помощью сочетания скобки и тире. Похожее применение имеют обратные вопросительные и восклицательные знаки в испанском языке, употребляемые в начале предложения. Поскольку автор не оставил ключей для понимания первой драмы (в отличие, например, от последней «Лидантю фарам», где 
есть предисловие с кратким описанием используемых автором изобретений [Zdanevič 2008: 625]), можно выдвинуть также гипотезу о дополнительной букве («сь»? «ть»?). Эта буква должна располагаться между «с» и «т»- судя по первой встрече этого символа в речи второго разбойника (рис. 2), где он произносит алфавит.

\section{фтарой}

\section{ф? хцчші ш ьъыы өз юя?}

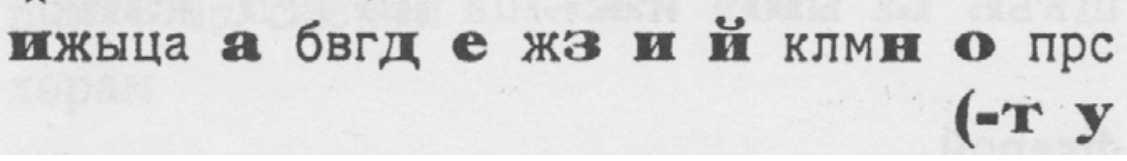

Рисунок 2. Алфавитное высказывание разбойника [Zdanevič 2008: 484]

В тексте встречается три раза одна открывающая скобка. Во всех случаях это заумный текст персонажей. Он используется одним и тем же способом, похожим на употребление символа «(-», в конце строки. В одном случае очевидна функция конкретизации: «янко банка казыбланка кыпабланка (шахматист» [Zdanevič 2008: 489]. Вероятно, речь идет о Хосе Рауле Капабланке, третьем чемпионе мира по шахматам.

В двух других случаях «( ыкикики» и «( юяе» мы наблюдаем пробел между открывающейся скобкой и первой буквой слова. Скорее всего, автор имеет в виду другой символ, ослабленный «(-». В пользу этой гипотезы говорит использование символа «скобки с пробелом» (рис. 3) таким же способом, как и «(-» для «( яюе» - в соседних «абзацах», имеющих схожую структуру, мы видим применение символа «(-» в схожих позициях как «( яюе». На рисунке 3 сравните конец строк: $4,7,10$.

Тире (дефис) Зданевич использует в двух случаях. Во-первых, как часть символа «(- ». Всего в драме находится 8 употреблений этого символа в заумной речи персонажей - как хоровой, так и индивидуальной. Символ находится в конце строки - обычно в начале последнего слова. В одном случае (рис. 1) символ используется в таблице схожим образом в строке, сдвинутой вправо (очевидно, являющейся специфическим продолжением предыдущей строки) в предпоследнем слове. Это употребление подсказывает, что роль у символа «(-», скорее, интонационная, как у апострофа, чем завершающая предложение, как у восклицательного знака. Во-вторых, тире используется в ремарках при определении порядка речи персонажей. Всего в драме 12 таких 
употреблений. В драмах Ильязда обильно используются хоровые партии. В ремарках обычно указываются исполнители с приписанными им номерами (рис. 4). Эти номера должны, по идее, использоваться по ходу произведения в заумной речи персонажей, чтобы было понятно, кто что говорит. Однако реально они не употребляются.

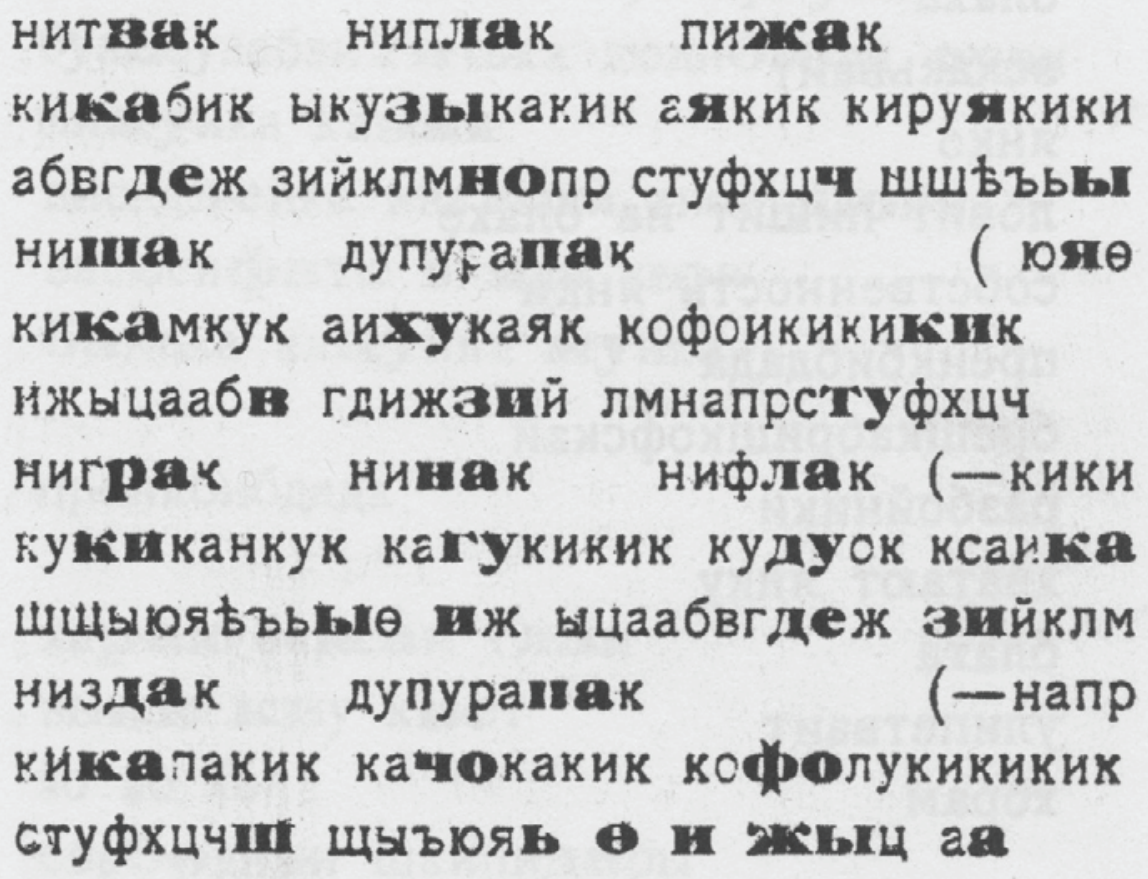

Рисунок 3. Использование символов «( » и «(-» [Zdanevič 2008: 487]

\section{первай фтарой \\ аркестрам}

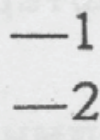

Рисунок 4. Приписывание порядковых номеров персонажам в хоровых партиях [Zdanevič 2008: 484]

В драме в речи персонажей эти номера использованы только один раз (рис. 5), причем в этом случае в ремарках соответствующая нумерация отсутствует. 


\section{шок тук моб -1 бличкк мутикикавута бликутжутара-2 аб вг де жз ий кл мн апр ст уф -3}

Рисунок 5. Использование порядковых номеров в хоровых партиях [Zdanevič 2008: 493]

Скорее всего, это сделано автором с умыслом. Драма Ильязда сопротивляется изучению, расставляет ловушки для исследователей: на этапе интерпретации и анализа мы встречаемся с эпатажной иронией создателя текста - одного из лидеров русских футуристов.

Вопросительный знак используется в тексте драмы 13 раз. Два употребления конвенциональны - в конце ключевой фразы, исполняемой героями произведения хором «динавзять круля?» [Zdanevič 2008: 486-487] (наш перевод: «где нам взять короля?»). Напомним, что действие пьесы происходит в Албании, где разбойники сажают на трон первого попавшегося человека, которым оказывается Янко, что отражает исторические события того времени и пародирует характер друга Ильязда - Янко Лаврина [Marzaduri 1982].

Остальные употребления вопросительного знака находятся в заумных фразах разбойников в начале произведения [Zdanevič 2008: 483-484]. Причем 6 употреблений (более половины из оставшихся 11) находятся в одной фразе «фтарого» разбойника. В этой фразе (рис. 6) мы видим вопросительный знак почти после каждого слова и даже после отдельных нечитаемых букв вроде твердого и мягкого знака - очередной эпатажный привет от автора-футуриста.

\section{лмн? оп рст? уф хцчшщ? ћ? '5? б?}

Рисунок 6. Использование вопросительных знаков [Zdanevič 2008: 483]

Разбойники говорят фразами, выстроенными из букв в алфавитном порядке, второй разбойник отвечает первому, частично повторяя его же «алфавитное» высказывание. Автор с помощью вопросительных знаков передает коммуникативную ситуацию повторения фразы в форме вопроса. Второй разбойник как бы переспрашивает, подвергает усиленному сомнению высказывание 
первого разбойника. Причем часть вопросительных знаков, как и остальных букв выделяется полужирным - для усиления этого сомнения. Мы не можем понять смысл предложений разбойников, и вряд ли он есть в алфавитных высказываниях, но из-за нестандартного использования пунктуационного знака, а также алфавитной структуры и приема повтора мы можем уловить остаточную эмоцию - сомнение.

В двух местах текста драмы автор использует таблицы (рис. 1, 7). Они состоят из двух столбцов, разделенных вертикальной чертой, которую можно также рассматривать как специфический знак препинания. Первая таблица относится к хоровому чтению, исполняемому персонажами «пренкбибдада», «брешкабришкофскай» и разбойниками, которые «стаят аркестрам». Левый столбец состоит из трех строк заумного текста, которые по идее, должны исполнять герои пьесы, скорее всего, одновременно. Справа - их же партия, состоящая из одной строки, которую надо пропеть с особой силой всем вместе, что подчеркивается увеличенным шрифтом и тремя знаками тире, соответствующим участникам хора.

Вторая таблица (рис. 7) в правом столбце содержит полностью идентичный этому же столбцу первой таблицы текст (иЗЕж), и сам повтор, оформленный столь нетривиально, говорит об особом статусе этого текста (в последней драме цикла «Лидантю фарам» похожую функцию выполняет слово «мамин» в конце речи «святого»- очевидно «аминь» [Zdanevič 2008: 629]). В левом же столбце на этот раз находится ремарка «убигают», а не какой-либо заумный текст персонажей, как в первой таблице. Автор играет, нарушая им же созданные правила и закономерности.

\section{убигают}

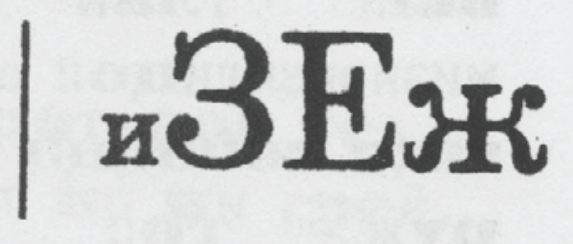

Рисунок 7. Использование таблицы с ремаркой [Zdanevič 2008: 494]

Текст драмы «Янко крУль албАнскай» является воплощением идей русского футуризма о создании нового поэтического языка и отражает актуальные для начала XX в. дискуссии об орфографической реформе. Автор принципиально использует ограниченный набор классических знаков, вводит новые способы членения текста. Отсутствие в драме некоторых знаков препинания становится значимым. Можно говорить об использовании минус-приема в поэтике Ильязда. Функции знаков препинания (в том числе выразительная, смысловая 
и интонационная) перераспределяются между выделенными полужирным буквами и собственно знаками. Членение текста на элементы производится не с помощью точек, запятых, а с помощью расположения элементов текста в строки, используются пробелы, особая композиция текста. В тех случаях, когда появляется знак препинания, он нагружается новым смыслом, релевантным только для данного текста. Пунктуация в тексте авангардного произведения играет особую роль, ее элементы переозначиваются.

Зданевич ставит перед собой задачу: выстроить футуристический заумный текст, используя минимальные средства языка.

\section{Литература}

Gik A.V., 2019, Osobennosti poètiki dram I. Zdaneviča: tipografičeskoe pis'mo dramy «Ânko krul albanskaj» [in:] A.A. Borovskaâ (ed.), Velimir Hlebnikov i mirovaâ hudožestvennâ̂ kul'tura. Materialy XIII Meždunarodnyh Hlebnikovskih čtenij, posvâsënnyh 80-letiû so dnâ roždeniâ professora Gennadiâ Grigor 'eviča Glinina, Astrahan': Izdatel'skij dom «Astrahanskij universitet», pp. 38-42.

Kručenyh A.E., Hlebnikov V., 2000, Slovo kak takovoe [in:] Literaturnye manifesty ot simvolizma do naših dnej, Moskva: XXI vek - Soglasie.

Marzaduri M., 1982, Sozdanie i pervaâ postanovka dramy «Ânko krul' albanskaj» I.M. Zdaneviča [in:] L. Magarotto, M. Marzaduri, G. Cesa (eds.), L'Avanguardia a Tiflis: Studi, Ricerche, Cronache, Testimonianze, Documenti, Venice: Università degli Studi di Venezia, pp. 21-32.

Zdanevič I.M. (Il'âzd), 2008, Filosofiâ futurista: romany i zaumnye dramy, foreword by R. Gejro, S. Kudrâvceva, ed. by S. Kudrâvceva, Moskva: Gileâ. 